\title{
A REVIEW OF THE CONTRIBUTION OF MULTI-CRITERIA ANALYSIS TO THE EVALUATION PROCESS OF TRANSPORTATION PROJECTS
}

\author{
S. BASBAS \& C.M. MAKRIDAKIS \\ Department of Transportation and Hydraulic Engineering, School of Technology, Faculty of Rural and Surveying \\ Engineering, Aristotle University of Thessaloniki, Thessaloniki, Greece.
}

\begin{abstract}
It is well-known that a transport project is of multi-dimensional importance. However, the economic dimension of its effects dominates the evaluation of a transport project, in many cases, and less attention is given to other non-economic parameters. Within the framework of this article, the contribution of multi-criteria analysis (MCA) techniques to the evaluation of a transport system is presented and discussed. Their relative advantage is that they include not only economic criteria but also other qualitative criteria such as the environmental impacts. The latter is a very important factor in the evaluation process because it is directly connected to the sustainable character of the transport project each time. Case studies concerning the implementation of MCA techniques in the transport sector worldwide are also presented. A comparative evaluation of MCA techniques is also included in the article to assist in the selection process of the most appropriate technique(s) for a transport project.

Keywords: analytical hierarchy process, decision-making, multi-criteria analysis, transport evaluation process.
\end{abstract}

\section{INTRODUCTION}

The quite often irrational development of the transport sector poses a danger for the environment and the quality of life. The effects of this irrational development include traffic congestion, the increasing number of accidents, environmental pollution, the all-increasing energy requirements and so on. Awareness about the environmental problems has increased not only among scientists, but also within the society in general. Therefore, there is a need for actions to secure a sustainable environment in general and a sustainable transport system in particular.

Sustainable development can be defined as the "development that seeks to meet the needs of the present without compromising the ability of future generations to meet their own needs" [1]. In general, the term sustainability is used to refer to the maintenance of the functions of the earth's systems and its concept provides a central focal point to determine the fundamental orientation for the solutions of complex problems. From another perspective, sustainable development implies economic development in harmony with nature without compromising the environmental basis of human life. The overall objective is to secure and increase the quality of life for all the people.

On the other hand, today only few researchers would dispute the assertions that transport evaluation process is extended beyond the classical model: optimizing the economic parameters. It is well accepted that many conflicting aspects should be taken into account, especially those related to the concept of sustainability. Therefore, for the transport sector in particular, the demand for sustainable development imposes the usage of criteria with non-monetary dimensions in the evaluation process, such as the environmental effects. It is notable that the environmental performance of the transport sector has been the subject of many recent studies [2]. These studies tend to concentrate on the various aspects of the environment, such as the energy use and the emissions of the vehicles. Additionally, sustainability in the transport sector requires explicit decisions and evaluation processes. The evaluation process of transport projects is in general characterized by conflicting objectives, quantitative

(C) 2007 WIT Press, www.witpress.com

ISSN: 1743-7601 (paper format), ISSN: 1743-761X (online), http://journals.witpress.com DOI: 10.2495/SDP-V2-N4-387-407 
and qualitative criteria, uncertainty with respect to the decision parameters, irreversible processes, the existence of several stakeholders with different preferences, high risk and urgency. All these factors increase the complexity of the evaluation process. The more complex the problem of transport evaluation is, the greater the need for a methodological tool that allows for compromises instead of searching for solutions that optimize a single criterion. This leads to the necessity for an approach that uses all the criteria.

Multi-criteria analysis (MCA) is an approach that takes into account a set of objectives and criteria that can be conflicting, multi-dimensional, incommensurable and incomparable. The information concerning the effects of the decision options can be both uncertain and non-quantitative. As the decisions in the field of sustainable development are often of this nature, MCA may be considered a useful decision aid tool. In that respect, the scope of this article is to present the role of MCA techniques in the evaluation process of transport projects and also to indicate their importance to satisfy the overall target of sustainability. The article includes a presentation of the existing MCA techniques. It is established that a great number of techniques has been developed to deal with different transport evaluation problems. The article does not report all the existing techniques, but the most commonly used in the transport sector.

Within the framework of the article, case studies concerning the use of MCA in the evaluation process of transport projects are presented based on literature review. The applications that are associated with transport evaluation problems on a global scale justify the usage of MCA and provide examples of the integration of the different dimensions and perspectives of sustainability in the decision process. The existing MCA techniques are not always sufficient for all the transport-related problems. Therefore, the selection of the most appropriate MCA technique itself tends to be a multicriteria problem. In that respect, it was considered necessary to perform a comparative evaluation of MCA techniques, which is also presented in the article.

It should also be pointed out that the article is an extensive review of existing contributions published on the topic of MCA. It embodies all the information gathered about the methodology of MCA in the evaluation of transportation projects, in particular. Based on the review of the literature, a comparative evaluation of MCA techniques is performed. In that respect, the article aims to offer guidelines about the selection of the appropriate technique and to convince the reader that the application serves the global target of sustainability. It is considered that the article satisfies both the targets.

\section{EVALUATION OF TRANSPORT PROJECTS AND THE ROLE OF MCA}

\subsection{Evaluation of transportation projects}

The evaluation of a transport project has two basic targets: (a) to justify its necessity or the investment needed and (b) to compare two or more alternatives of the transport project, taking into account various criteria and also the views and preferences of the users and the decision makers. The basic steps for the evaluation of a transport project include: the socio-economic cost benefit analysis (CBA), MCA and financial analysis. Both CBA and MCA concern the feasibility of the project. They examine the impacts on the society, the users of the transport infrastructure, etc. The basic difference between them is that CBA focuses on the monetary dimension of the impacts for the lifecycle of the project, while MCA pays attention to other non-monetary impacts. In that respect, it accomplishes a global evaluation of the project and contributes to the sustainable development of the transport sector. The financial analysis is generally performed from the private sector point of view 
and concentrates only upon the revenues and the expenses related to the transport project for the operation period under discussion.

\subsection{The role of MCA in the evaluation of a transport project}

\subsubsection{Scope and benefits of MCA}

Sustainable development can be defined as the transformation process which takes into account environmental as well as social and economic objectives [2]. On the other hand, the choice process of a transport project against the background of the concept of sustainability should be based on a broad set of criteria that allows the simultaneous consideration of the project's impacts from different and contradictory viewpoints, notably economic, social and environmental. The MCA approach seeks to take explicit account of all the conflicting criteria and contradictory views. Additionally, it assists the decision makers to learn about the transport evaluation problem in question. The principal objective is to guide the decision makers in identifying, often through extensive discussion, the preferred course of action (through organization, synthesis and appropriate presentation of information).

In the decision aid theory, the main assumption embodied is that the decision makers are rational and prefer the solutions that maximize their welfare. In transportation projects there are multiple objectives to fulfil, and consequently disagreements frequently appear among the different parts about the scope of the project or the procedure to be followed. The actors participating in the process often disagree on the objectives or the relative importance of the criteria. Disagreements tend to appear in the data processing or the analytical tools to be used. Past experience reveals that the conflicting views complicate the process and tend to increase the total required time [3]. The benefit of applying MCA is that it provides a framework that allows the often conflicting and contradictory views to be addressed simultaneously, in a fully transparent way. In that respect, MCA leads to better-considered, justifiable, explainable and transparent decisions. Complex interactions and multiple objectives make the process more complicated and increase the analytical endeavour. The demand for sustainability requires the establishment of a systematic and transparent process with interactions between analysts and decision makers on a first level and between decision makers and social groups on a second level. In MCA, the choice of the objectives and criteria that any decisionmaking group may suggest are open to analysis. In that respect, the concept of sustainability, which is translated to the understanding and the incorporation of the environmental perspective of the project, is feasible.

Additionally, the use of MCA helps to organize, manage and in many ways simplify the immense amount of technical information, which is often available. This benefit is of enormous importance, since nowadays, even in developed countries, analysts have to deal with a great volume of environmental data. Sometimes the relevant data may not be available or may be too expensive to collect. Difficulties often appear in management and analysis of these data. MCA and the software developed facilitate this process.

Another benefit of the procedure is that the process can be fully controlled. Scores and weights are given based on established techniques. In particular, the performance measurement of the alternatives against the environmental criteria can be given according to environmental experts. The values may also be cross-referenced to other sources of information and the possibility for modifications at a further stage is given if it is felt that the concept of the sustainability is not served.

From what is mentioned above, one can reach to the conclusion that MCA is a suitable means to analyse the environmental impacts and other non-economic parameters of a given transport project and facilitate the process of sustainable development. 


\subsubsection{Drawbacks of MCA}

The methodology of MCA is of immense importance for the sustainable development of the transport sector as discussed in the previous parts of this article. Nevertheless, the review of the literature revealed that MCA may present some drawbacks. Hence, the special analyst should be aware of the potential disadvantages so that the outcome of the analysis is to serve the scope of sustainability. In that respect, the object of this part of the article is to present the disadvantages of the methodology of MCA that were reported.

The process of transforming qualitative data into quantitative data may be a strong disadvantage of MCA. The review of the applications of the methodology indicated that there is not a certain way to deal with qualitative data [4]. On the contrary, a great deal of different techniques was developed to deal with this particular problem of transforming qualitative data into quantitative data in the decision process as further discussed in the following parts of this article. Although most of these techniques offer an adequate framework to treat jointly the qualitative and the quantitative information and cope with different problems of evaluation, the analyst in many cases follows a procedure or a technique that he is familiar with, which is not necessarily the most appropriate for the evaluation problem in question. On the other hand, transforming qualitative data into quantitative data is debatable and many researchers would express strong disagreements against the outcomes of the process [5]. It should also be pointed out that the presence of many different techniques is partly a consequence of that specific disadvantage of the methodology in question [6]. The different techniques tend to treat the problem of transformation in a different way and therefore they address different decision-aid problems.

Furthermore, the diverse MCA techniques do not always lead to the same results. If the application of different techniques to a certain evaluation problem produces large discrepancies, then this may increase the analytical endeavour and impose a greater deal of difficulty to the process of identifying the best or the most appropriate alternative to satisfy the target of sustainability [7]. In practice, some analysts and practitioners are incapable of justifying clearly their choice of one MCA technique rather than another one. A sort of familiarity and affinity with a specific method may motivate this choice. The problem is that this behaviour is translated in practice by adapting the evaluation problem to the technique and not the opposite, which is a non-productive attitude. It is important to know how to use and apply a certain technique, but this is not adequate to apprehend all the transport assessment issues and furthermore this is not sufficient to satisfy the goal of sustainability.

Additionally, another drawback of the methodology is related to the possibility of handling the different types of uncertainties arising in the decision process in an adequate way. The alternatives considered and the criteria used impose a certain deal of uncertainty upon the evaluation process. To achieve the global goal of sustainability, it is necessary to acknowledge in a MCA the subjectivity and uncertainty in the selection process of alternatives, criteria and criteria weights to transparently model the assessment process [8]. Furthermore, the modelling of the decision-makers' preferences is a crucial part in the decision-aid process. Consequently, special emphasis should be placed on handling the uncertainties associated with these preferential parameters. However, the uncertainties that may arise in a MCA are often underestimated [9]. The occurring uncertainties can be classified in many different ways. Researchers have suggested a distinction between 'data uncertainties', 'parameter uncertainties' and 'model uncertainties' [10]. The term 'data uncertainties' suggests the uncertainties of the input data to a model. 'Parameter uncertainties' refer to model parameters, such as the weighting factors of a MCA model. Finally, 'model uncertainties' are the uncertainties that arise from the fact that models are ultimately only simplifications and approximations of reality. The different types of uncertainty that may arise at the evaluation procedure may explain the great deal of different techniques, which is partly a consequence of this characteristic of MCA. 
It is also notable that the simplifications of the problem, to make it understandable for all the persons involved in the process, reduce the complexity on one hand but, on the other hand, cause loss of important information. Consequently, attention should be given to the outcomes of the analysis to reflect the real nature of the problem and satisfy the concept of sustainable development.

Another characteristic of the methodology that may be considered as a drawback is that the outcome of the analysis highly depends on the selected weights of the criteria used. The weighted factors reveal the relative importance of the chosen criteria and the goal(s) of the evaluation study. For instance, giving a higher weight to environmental criteria and a lower weight to economic criteria suggests that the goal of the project in question is the protection of the environment and less attention is given to the economic effects. In practice, there is always the danger that the analyst might oversimplify the problem and use a set of fixed criteria weights independent of a certain goal of the project in question or adopt criteria weights that were used in other evaluation studies without applying certain technique to define the weights. Similar transport projects may have different goals and therefore the use of equal factors may lead to results that do not satisfy the scope of the analysis. Additionally, it is important to remember that a slight modification of the weights of the criteria used may alter the outcome of the analysis.

Additionally, the application of the methodology in question to certain evaluation problems may provide indistinguishable results when comparing or ranking the different alternatives. For instance, an alternative with a single strong performance in a selected criterion and weak performances in other criteria would score the same as another alternative which has all partial effects in a medium performance [11].

Furthermore, the possible presence of cycles or the rank reversal phenomenon is another strong disadvantage of MCA. For instance, applications of the methodology to evaluation problems indicated that an alternative $\mathrm{a}$ is preferred to $\mathrm{b}, \mathrm{b}$ is preferred to $\mathrm{c}$, but $\mathrm{c}$ is preferred to a [5]. Additionally, a similar problem was highlighted for analytic hierarchy process, where the introduction of a new alternative modified the ranking of the other alternatives [12].

It can be concluded that the methodology of MCA presents certain drawbacks. Hence, the special analysts should be always aware of the possible problems that may arise and of the fact that environmental concepts vary on which variables are important and which are not. Additionally, the analysts should lay special emphasis on the treatment of uncertainties and the procedure of transforming qualitative data into quantitative data.

\subsubsection{The history of MCA}

From the first steps of humanity, decision-making was a multi-dimensional process as many factors (criteria) needed to be taken into account. The process did not have a mathematical expression and it was only facilitated from the decision-makers' experience and the special needs of the problem in question.

The history of MCA as a methodological approach started in the 18th century when Condorcet published his book about decision-making by a plurality of voices. In 1896, Pareto's study 'Cours d'Economie Politique' set the fundamental bases for further theoretical development of the methodology. The study introduces the term efficiency, which is considered to be of immense importance nowadays for the evaluation of transport projects.

The publication of von Neumann-Morgenstern's book about game theory in 1944, the introduction of the social choice theory by Arrow [4], the theory of revealed preferences that was presented in 1938 by Samuelson [13] and the psycho-mathematical aspects of the individual decision by Luce and Raiffa in 1957 [14] and Fishburn in 1970 [15] had significant influence on the theoretical base of the methodology. 
An important turning point was signalled by Roy in 1968 [16] when he presented the outranking technique ELECTRE, which is the first of a sequence of techniques that express the French school of theory in MCA and is widely used nowadays for the sustainable evaluation of transport projects on a worldwide scale.

In the 1960s, MCA began to emerge with its own vocabulary and problem formulation and the first applications started to appear. In 1972, the first congress on 'Multiple Criteria Decision Making' took place in South Carolina. It should be reported that until then the dominant approach in the evaluation was the search of an optimal choice that maximized an economic function. Therefore, the introduction of MCA in case studies was not obvious and was quite difficult to be accepted from all parts.

In 1976, Simon presented his theory about bounded rationality [17]. The theory states that a decision maker chooses a satisfying solution rather than an optimal one. In 1976, Keeney and Raiffa broadened the utility theory in the presence of multiple criteria [18].

Many researchers would suggest that the most important time point in the history of MCA in the evaluation of transport projects was in 1980 when Saaty presented the analytical hierarchical process [19]. This technique is most widely used in transport evaluation and highly supports the concept of sustainable development.

In the late 1980s, a large number of techniques were developed and the number keeps increasing, as there are different types of problems that cannot be addressed by the existing techniques. By that period, MCA techniques gained a worldwide reputation and are nowadays promoted by different societies. On the other hand, the development of user-friendly software increased the methodology's attractiveness in the evaluation of transport projects.

\subsubsection{Approaches in MCA}

Generally speaking, there are two basic approaches for the process of MCA. The two groups of philosophies that may be distinguished are the 'Platonic' and the 'Aristotelic' approach [3]. The basic difference is associated with the desirable outcome of the evaluation study. Both philosophies can fulfil the concept of sustainability. Which philosophy is to be applied highly depends on the actors of the MCA and the expected result of the evaluation.

The Platonic approach suggests that there is a 'best' alternative - decision. This philosophy assumes that a well-established evaluation system is offered to the decision maker so that he or she has the potentiality to fully rank any set of events. It is suggested that the process, which ends in a majority vote for each alternative, should settle any dispute between the decision makers.

On the other hand, the Aristotelic approach tends to eliminate the feasible choices into those that are less satisfactory. The main assumption is that in the real-world transport evaluation problems there is no 'best' solution, because many contradictory views should be embodied and the complete satisfaction of all conflicting parts cannot be accomplished. Therefore, the basic idea of the philosophy is to identify a solution that eliminates strong oppositions among the decision makers. A complete ranking of the alternatives is not required. This approach aims at constructing a formal system, which can be a useful tool in the transport evaluation process, to understand, specify and model one's preferences in order to increase the coherence of the process itself.

\subsubsection{Stages in MCA}

Regardless of the transport project that is evaluated and the technique that is applied, there is a certain course of actions that should be followed to perform an MCA. This part of the article presents, in short, the stages that need to be carried out to apply the methodology of MCA in the evaluation of a transport problem. 
The first and immensely important stage is to clearly define the problem in question. In this stage, the aims of the transport project are determined and the connection with the concept of sustainability is given. In this step, the assumptions of the study are clearly stated. The identification of the actors of the analysis, people who take part at the process of the decision-making, should be performed. Environment specialists should definitely take part in the process as their knowledge and experience can be further used to translate the specific environmental data of the project in question into valuable information and facilitate the analysis.

The second stage of the analysis is to define and list the set of options to be considered. This process is not obvious as, theoretically, there is a great number of alternatives that could be considered as acceptable. The reduction of the number of options for further consideration to a smaller number of alternatives is always desirable at this phase of the analysis. This stage is highly influenced by the knowledge and the experience of the special analyst in similar projects, or even by his intuition. Legal and other restrictions should be taken into account. Some researchers would suggest that identifying the alternatives means to organize the ensemble of what is feasible, regardless of the consequences, but this is not always the case. The process should propose the solutions that fulfil the concept of sustainability. Therefore, it is advised that the solutions that have harmful environmental impacts should be excluded at this stage of the analysis. It should be noted that subsequent steps of the MCA may demonstrate that none of the alternatives is acceptable or in accordance with the idea of sustainability. Therefore, the possibility of adding or modifying the options as the analysis progresses should be kept in mind.

The next stage of the analysis is the selection of the criteria according to which the evaluation of the transport project may be performed. The identification of the criteria may be performed by the predefinition of what would distinguish a sustainable solution from a non-sustainable solution. The relative advantage of the MCA methodology is that it can embody criteria related to the concept of sustainability. Consequently, the environmental impacts should be used as criteria from the special analyst. Some of the criteria could be the safety level, noise, air or water pollution, energy consumption, aesthetics, impacts on flora, impacts on fauna, etc. [20]. This stage is also supported by the views and interests of the decision makers. Additionally, the chosen criteria should obey certain rules. In short, the criteria should be complete, operational, redundant, consistent and mutually independent. The number of the chosen criteria should serve the scope of the analysis. An excessive number does not necessarily lead to improved outcomes, but always adds analytical effort and increases the total cost [21].

The structure of the performance matrix is the next step. The performance matrix is a matrix that presents the performance of each alternative against the chosen criteria. Although the performance may be given in many different formats, the use of numerical values, usually between 0 and 100 , is suggested.

The selection of the weights is the next step. The weighted factors reveal the relative importance of the chosen criteria. These factors express the decision-makers' preferences. One should keep in mind that environmental concepts vary depending on which variables are important and which are not important. Consequently, a very important issue that needs to be pointed here is that the way questions are asked about individuals' preferences proves to be very imported. In other words, a well-designed questionnaire should be prepared. Although there are many techniques developed for the definition of weights, the most commonly used is the pairwise comparison. To achieve the goal of sustainability, the weights given to criteria that express the environmental impacts of the transport project should be relatively high, i.e. translated into the approval of projects that satisfy the global demand for sustainable development and into the rejection of projects that tend to have harmful effects on the environment. 
The next stage involves the determination and application of an amalgamation rule. This rule translates the previous values given into a single overall weighted score or ranking for the available options. This generally requires the application of a model associated with the MCA technique chosen.

Finally, it is always advisable to conduct a sensitivity analysis to examine how vulnerable the outcome of the MCA is to changes of certain parameters or variables. The sensitivity analysis is necessary to deal with uncertainty that is inevitably embodied in the available data. It is noted that if the changes do not affect the outcome, this can be a strong indication that the proposed solution or set of solutions serve the concept of sustainability.

\section{MCA TECHNIQUES}

In the last decades, a large number of MCA techniques have been proposed to facilitate the decision aid process. The number of techniques is constantly increasing due to many reasons. An important reason is that there are many types of decision aid problems and each transport evaluation problem should be considered as an individual one with its specific goals, assumptions and limitations.

Some of the techniques surveyed have been applied to the evaluation of transport projects on a global scale. This part of the article reports the most commonly used MCA techniques. It should be stated that it is practically impossible to survey all the different MCA techniques and this is beyond the purpose of this article. It is considered that the number of techniques presented here satisfies the scope of the article.

Pardalos proposed a grouping of MCA techniques that considers not only the models developed but also the way the models are developed [22]. Starting from this grouping a modified categorization is suggested. In this article, the analytical hierarchy process is presented separately as it is considered to be the most widely used MCA technique in the evaluation of transport projects that contributes to the target of sustainable development.

\subsection{The analytical hierarchy process}

The analytical hierarchy process (AHP) was developed by Saaty in 1980 [19] and is considered by many practitioners and researchers to be the most suitable technique to accomplish the concept of sustainability. Due to its transparency and valuable mathematic structure, the technique has an important practical value. Additionally, the development of user-friendly software, such as Expert Choice and Hipre 3+, increases the attractiveness of AHP.

The technique suggests a hierarchical structure of the problem into levels. The pairwise comparison both for the criteria and for the performances of the alternatives against the criteria is also suggested. AHP proposes a linear additive model that estimates the total score of each choice. In that respect the full ranking of the alternatives is accomplished.

A benefit of AHP is the possibility to express qualitative and quantitative performances in a transparent way and the possibility of expression of more than one decision makers for the process. In that respect, the use of the environmental consequences of the transport project in question is feasible in a clear and explicit way. The possibility to embody conflicting views is of immense importance as there is a great deal of subjectivity in environmental issues and personal views may vary on the environmental concepts. Additionally, most users find the pairwise comparison form of data input straightforward and convenient, which in turn explains the extensive application for the evaluation of transport projects.

On the other hand, the technique presents some important drawbacks, such as the rank reversal phenomenon [12] and the absence of thresholds. The thresholds, in particular, ensure that the 
proposed alternative achieves a minimum level of performance at the used criteria. For instance, the use of a threshold may ensure that the proposed transport project causes the minimum of environmental effects. Therefore, modifications of the technique are suggested to deal with such problems [23-25].

\subsection{The outranking techniques}

The outranking concept was first introduced by Roy in 1968 when he presented the ELECTRE technique [16]. Since then, a large number of outranking techniques have been developed and many have been applied in transport projects, especially in Europe.

This group of techniques performs a pairwise comparison between every pair of alternatives. The basic principle of the outranking techniques is that choice A outranks choice B if there is enough evidence, according to the decision-makers' views, that A is at least as good as B, while there is no overwhelming reason to refute the statement.

Typically, the procedure is developed in two stages. In the first stage, the outranking techniques use an outranking relation between the alternatives. The suggested relation is the mathematic formulation of the preferences of the decision makers. The relation demands the predefinition of certain parameters, the preference, the indifference and the veto thresholds. In the second stage, the relation is exploited and the introduction of certain mathematic rules helps the analyst to arrive at a conclusion. The outranking relation has the drawback that it cannot always guarantee the complete ranking of the alternatives. Another drawback is the possibility of 'circles' in the ranking. That means that if choice $\mathrm{A}$ is as preferable as choice $\mathrm{B}$ and choice $\mathrm{B}$ is as preferable as choice $\mathrm{C}$ that does not necessarily entail that choice $A$ is as preferable as choice $C$ [5].

Some of the most commonly used techniques are: ELECTRE I, ELECTRE II [26], ELECTRE III, ELECTRE IV, PROMETHEE I-II [27], Condorcet, N-TOMIC [28], PROAFTN [29], ORESTE [30], Regime Analysis [31], SIR [32], TOPSIS [33] and VICOR [34].

\subsection{Techniques based on the utility theory}

This group of techniques uses the utility theory to reach a conclusion. The general process includes the definition of a utility function for each criterion. This function translates the performance of each alternative against the criterion in question in a single value. The weighted sum of those values is the total score, the overall utility, for each alternative. The higher the score the most preferable is the alternative.

The benefit of these techniques is that they allow the modelling of the non-linear behaviour of the decision-makers' preferences. Additionally, the use of qualitative criteria does not require their direct quantification.

The definition of the utility function is a hard process based on the cooperation of the decision maker with the special analyst. For the explicit definition, a great amount of information is required related to the preferences and interests of the decision maker. This is a disadvantage of those techniques, as most decision makers do not wish to fully reveal their personal system of views. A special survey is required which means that the total cost of the analysis increases. Some of the well-known techniques are: UTA [30, 35], IDRA [36], SMART and SMARTER.

3.4 Multi-objective mathematical programming

An alternative approach to MCA problems involves the optimization of many objective functions by the use of mathematical programming. It is suggested that there is no optimum solution but only an 
alternative that satisfies the limitations defined and maximizes or minimizes at the same time the objective functions in question. The search of the solution is limited to the set of the feasible solutions, which is called the efficient set.

The procedures developed may be interactive or iterative. Initially a solution is presented to the decision maker as a result of the previous procedure. If he or she is satisfied then the process is complete. If not, additional information is required related to the predefined targets. Some important techniques are: DEA [37], the constrained technique and the surrogate tradeoff technique [38].

\subsection{Techniques dealing with imprecision and inconsistency of data}

In many types of real-world decision-making problems, the scores of the alternatives against the selected criteria or the numbers that express the weight of the criteria cannot be handled as exact numbers. This is often the case for problems having their real outcomes in the future, such as environmental decision problems. The use of accurate values would oversimplify the problem.

In the evaluation process of a transport project, in particular, the need to deal with the presence of inconsistent or imprecise data is a common issue. This information needs to be interpreted and expressed quantitatively, a task usually not easy for the special analyst to fulfill. This imprecision is sometimes treated as a probability, where a stochastic approach is applicable. However, this does not always yield the desirable results. Therefore, several alternative approaches have been proposed to deal with the problem and the relevant techniques can be applied with more or less success depending on the specific problem in question.

An interesting modification of the PROMETHEE technique is the F-PROMETHEE technique [39], which suggests the introduction of the fuzzy set theory, presented by Zadeh in 1965 [40]. Another approach is the SMAA technique [41], which can be useful in the evaluation of the environmental effects of a transport project. The rough set theory [42] may also be a way to deal with problems in the presence of inconsistent data.

It should be stated that applications of the fuzzy set theory in the evaluation of transport projects are limited due to the strong oppositions developed. A large segment of the MCA community would claim that there is lack of convincing arguments that the imprecision captured through fuzzy sets and the mathematic formulas developed are a reliable approach to the problem [5, 21].

\subsection{Other techniques}

In the literature, one can find other suggested approaches to deal with the problem of the evaluation of a transport project. Some interesting techniques that could not be placed in one of the previous categories are: SAW, WP, the flag model, QUALIFLEX [43], EVAMIX [44], BORDA and the minimum tolerance technique [45].

\section{CASE STUDIES}

The objective of this part of the article is to present some characteristic applications of the MCA methodology to the evaluation of transport projects. The case studies are based on the applications of the techniques discussed in the preceding section. However, this part of the article is not a simple report of the case studies. All the applications clearly emphasize the contribution of the MCA methodology to the sustainable development.

In that way, the reader may be convinced that the methodology in question accomplishes the goal of sustainability in real-world problems. Additionally, it can be stated that the presentation of the 
applications is a useful tool for the analyst seeking to evaluate a potential transport project, having sustainable development always as a target. On the other hand, by focusing on real cases the specifications and the limitations of transport projects evaluation were examined.

The presented case studies are associated with all transport systems. Some of them deal with infrastructure while some others with the operation of the system.

\subsection{Applications of the MCA methodology to urban and public transportation}

A great number of applications in the literature deal with the sustainable development of the urban transport system. It is well accepted that the evaluation of these projects should include all the potential consequences, monetary and non-monetary. The sustainable development of public transport in particular is considered of enormous importance as it satisfies the democratic right for transport.

An interesting case study presents an empirical procedure for the selection of alternative options for environmentally sustainable transport system in Delhi [46]. It was considered that to achieve an environmentally sustainable transport system, it is essential to rank the feasible options using the methodology of MCA, which was based on quantitative and qualitative criteria. The complete ranking of the four alternatives was accomplished using the AHP technique.

Another article presents a geographical information system (GIS) for the analysis and the evaluation of different transport policies [47]. This system is an effective tool that assisted transport administrators to enhance the efficiency of the transportation supply while improving environmental and energy indicators. The use of tool is demonstrated through a case study on the Greater Athens area in Greece.

The transit study performed in Singapore searched for the best alternative using MCA [48]. The principle aim was through an explicit process to decide about the potential plans of the transit system using eight criteria.

MCA was also used to evaluate the alternative fuel buses for public transportation in Taiwan [49]. It was considered that the results of the analysis could be further used to improve the environmental quality of major cities.

An empirical application on the planning of public transport systems for the city of Nijmegen in the Netherlands from an environmental perspective can also be found in the literature [50]. MCA was performed in combination with CBA to facilitate the process of sustainable development. The study offers a framework to integrate ordinal and cardinal information in multi-criteria ranking with imperfect compensation. The case study indicated that the final ranking of the alternatives depends on the elasticity of substitution between criteria; even in the situation that one criterion dominates all others.

Another article sets out the results of the studies for a proposal in Southeast London known as Greenwich Waterfront Transit [51]. The studies have established and evaluated options for the sustainable development of the public transportation system. The methodology of MCA was used according to the British Government's 1998 White Paper on Transport which lays particular emphasis on the five strategic objectives of the government's transport policy - environment, safety, economy, accessibility and integration.

An interesting case study is the one dealing with the evaluation of the rail transit network in Istanbul [52]. The process was imposed by the deficiencies observed in Istanbul's transportation system that necessitate the establishment of a sustainable transport system. MCA facilitated the procedure by organizing perceptions, experiences, knowledge, judgments and the forces that influence the decision in general into a hierarchical framework with an explicit goal, defined scenarios, well-accepted criteria and a fully justified choice of technique. 
The methodology of MCA was also applied in the optimization of the urban transportation system in European cities. The city of Poznan in Poland [53] and the city of Florence in Italy [54] are typical examples.

The evaluation of the performance of bus companies in Taiwan using an effective fuzzy MCA [55] is another application of the methodology in question. The subjectiveness and imprecision of the process were modelled as fuzzy numbers by means of linguistic terms. The underlying concept is intelligible to the decision maker and the computations required were simple and straightforward.

The Transecon research project lays particular emphasis upon the direct and indirect effects and impacts of transport infrastructure investments in 13 European cities [56, 57]. It includes the development of a methodology driven by a multi-disciplinary perspective to justify their contribution to sustainable mobility and intermodality.

\subsection{Applications of the MCA methodology to road transport}

The road transport sector has been overdeveloped in the past decades. This oversized development causes many harmful effects upon the environment. On the other hand, only few people would dispute the assertion that road transport affects our life enormously. Therefore, in many cases the special analysts seek to evaluate the projects on a multi-dimensional scale as a tool to promote sustainability.

A study examines the environmental impacts and costs of transport initiatives in Greece [58]. In particular, the case study deals with the appraisal of alternative road schemes in Agios KonstantinosKamena Vourla area for the PATHE motorway project. The framework developed comprises four steps: structuring weighting, rating and exploring. The MCA model uses an additive function providing simplicity and intuitive understanding of the results. Uncertainty is treated through fuzzy sets or through sensitivity analysis. The relative advantage of the evaluation model developed is its capability to look into different geographical areas with a different perspective and examine different time horizons of the environmental impacts.

Another case study, also performed in Greece, presents a fuzzy multi-criteria evaluation system for the assessment of tunnels vis-à-vis surface roads. The suggested evaluation model was applied to the western peripheral motorway of Athens [59]. The fuzzy hierarchical analysis was applied as a suitable means to deal with the high uncertainty of the evaluation environment.

Another article describes a research on the socio-economic and environmental impacts of advanced convoy driving on the motorway in the UK [60]. MCA was used in combination with CBA to deal with data that could not be expressed in monetary units.

MCA was also used in combination with the development of a GIS to evaluate the safety level along transportation corridors on the Hopi reservation in Arizona [61]. Additionally, a GIS multicriteria corridor evaluation methodology that facilitated the choice of a route corridor for a section of a proposed interstate highway connector in southeastern US may be found in the literature [62].

\subsection{Applications of the MCA methodology to sea transport}

A real case study dealing with the comparison of transport scenarios concerning the sustainable establishment of the maritime traffic policy in Greece can be found in the literature [63]. A detailed description of the MCA evaluation model is presented in the article, which enabled the analysts to take into account the multiple dimensions and points of view of the large group of actors involved. The key characteristic of the model was its flexibility to use different aggregation procedures along the nodes of the hierarchy of evaluation criteria. 
An approach to natural resource management that incorporates multiple objectives for marine protected area management is another interesting article [64]. The approach uses a framework based on MCA and involves stakeholders at all stages.

\subsection{Applications of the MCA methodology to air transport}

An interesting application developed a multi-criteria decision support methodology for evaluating airport expansion plans in Netherlands [65]. The aim of the study was to identify the best possible ranking of the four alternatives with respect to a predefined set of critical threshold values. The use of thresholds was related to a normative view of the concept of sustainability. More attention is paid to the question of how sustainability can be identified as a normative orientation for policy. In that respect, it was ensured that the chosen alternative achieves a minimum performance against all the environmental criteria and consequently that the suggested solution is generally the most sustainable.

\subsection{Applications of the MCA methodology to freight transport}

The freight transport sector affects the environment on a large scale, in terms of pollution and energy consumption. Therefore, the adoption of MCA is, in most cases, necessary to achieve the global goal of sustainability.

The optimal location of intermodal terminals in Europe is discussed in the EMOLITE project. One of the basic targets was to minimize the potential negative effects on the environment as a consequence of the expected increase of freight transport. To rank the suggested terminals, according to those targets, the decision support system used MCA that includes a simulation module using fuzzy logic.

4.6 Applications of the MCA methodology to the implementation of intelligent transportation systems (ITS)

The literature review revealed that the methodology of MCA is introduced many times to facilitate the implementation of ITS.

A study presents an MCA for the evaluation of alternative ITS in Oakland County [66]. MCA was used to compromise the often-competing preferences of the various groups sharing intense interests in transportation planning options, in general, and in ITS policy, in particular. Environmentalists joined the evaluation process and the analysis took into consideration auto emissions as an important criterion.

Another article provides a framework to evaluate the congestion pricing technologies using the methodology of MCA [67]. The technologies were evaluated under different conditions and the relevant data were obtained from demonstration projects in Europe.

Another study developed a typology to rank European inter-urban road corridors aimed at tracing the effects of advanced transport telematics on constituent road links [68]. The ranking of corridors according to the needs of telematics systems was achieved by means of MCA. It was considered that the implementation of those systems would contribute to sustainable mobility and that therefore individual treatment should be given to each road segment.

Finally, another article attempts to assess the various ITS technologies using the multi-criteria methodology [69]. 


\subsection{Other case studies}

An interesting application compares the various Dutch passenger transportation systems by studying their life cycle energy use [2]. The analysis facilitates the comparison of different transport modes from an environmental perspective, keeping in mind that modes are not always interchangeable.

The Regional Balkans Infrastructure Study (REBIS) focused on the sustainable development of a multi-modal Core Transport Network for the Balkan region [70]. The investments required to improve and develop the network both in the short and long term have been developed through a number of stages including a comprehensive MCA.

The Transport Infrastructure Regional Study (TIRS) in the Balkans also used the methodology of MCA [71]. The reasons were the preliminary level of definition of most projects, the lack of precise information, the imperfect knowledge of transport-demand perspectives, the large array in types of projects and the specific objectives of TIRS. The procedure was based on the ELECTRE technique.

A very interesting case study evaluates three high-speed transport systems in Europe, high-speed rail, transrapid MAGLEV and air passenger transport [72]. The principal aim of the study was through a MCA to emphasize both the complexity and the sensitivity of the procedure and to indicate which system might be preferable and under which circumstances. Therefore operational, socio-economic and environmental criteria were adopted and the TOPSIS technique was used to indicate the most preferable option.

\section{COMPARATIVE EVALUATION OF MCA TECHNIQUES}

This section of the article is devoted to the comparative evaluation of the most commonly used techniques of the MCA methodology. It is based on the results of an extensive comparative evaluation study [73].

The suggestion that each technique is suitable for all transport evaluation problems is a rather erroneous one. The study of the different MCA techniques reveals that despite the development of a large number of techniques, none of them can be considered as the optimum technique that is suitable to all transport evaluation problems. Each technique has its assumptions and hypotheses that limit its selection when someone deals with a given problem. Therefore, guidelines to choose each time the most appropriate technique are considered to be of immense importance. In that respect, the process of choosing the appropriate technique for a given transport project is highly supported and the goal of the sustainable development of the transport system can be accomplished. The information given here should be interpreted as guidelines that can be combinated with the experience and the knowledge of the transport planner, the designer of the MCA or the special analyst.

In practice, the choice is motivated by a sort of familiarity and affinity with the technique in question. The transport evaluation problem is adapted to the technique, while the opposite should take place. In other cases, analysts tend to use software without understanding the procedure. In that way the needs of the project are adjusted to the technique, while the technique should be adjusted to certain characteristics of the project. Hence, the problem is how to select the appropriate technique and furthermore the technique which contributes to the goal of sustainability. MCA analysts tend to use a technique that is familiar.

The selection of the technique is itself a multi-criteria problem, as there are many factors (criteria) that may be adopted to choose the most suitable one for a given transport project. Internal consistency and logical soundness, transparency, ease of use, data requirements, time and manpower resource requirements for the analysis process, ability to provide an audit trail and software availability are, in short, some criteria that may be used for the selection of the most appropriate technique. 
The scope of the study is a factor of enormous importance. For example, a different technique should be chosen if the scope is the definition of the best alternative or the classification of the options into categories.

The acceptance of the technique by the decision takers is also an important criterion. Some decision takers do not wish to fully reveal their personal preferences and views about certain issues. If he or she refuses to provide detailed information, then some techniques should be rejected.

Another criterion may be the data requirements and the total cost of application of the technique. The total cost should be compatible with the needs of the project in question. The best technique should not be more expensive than predefined.

The availability of software is also an important factor to consider. Software can save a great deal of effort and consequently money, a very important criterion for the professionals.

To deal with the problem of technique selection, Table 1 serves as a useful guide. This summary table informs in general the drawbacks and the benefits of the presented techniques. The last column provides some characteristic applications of the technique in question. In that respect, the reader may be further informed about the way a technique was applied to serve the concept of sustainability.

Table 1: Comparative evaluation of multi-criteria analysis techniques.

\begin{tabular}{|c|c|c|c|}
\hline Techniques & Advantages & Disadvantages & $\begin{array}{l}\text { Characteristic } \\
\text { applications }\end{array}$ \\
\hline AHP & $\begin{array}{l}\text { - Hierarchical structure of the } \\
\text { evaluation problem into } \\
\text { levels } \\
\text { - Complete ranking of the } \\
\text { alternatives } \\
\text { - Availability of user-friendly } \\
\text { software } \\
\text { - Compatible with other } \\
\text { techniques } \\
\text { - Flexible, transparent and } \\
\text { user-friendly } \\
\text { - Possibility to include views } \\
\text { of many } \\
\text { - Decision makers }\end{array}$ & $\begin{array}{l}\text { - The 1-9 scale is often } \\
\text { internally inconsistent } \\
\text { - The link between the } \\
1-9 \text { scale and the } \\
\text { decision-makers' } \\
\text { preferences do not have a } \\
\text { theoretical foundation } \\
\text { - Rank reversal phenomenon } \\
\text { - Absence of threshold } \\
\text { values }\end{array}$ & $\begin{array}{c}{[46,49,52,58,} \\
59,61,62,66]\end{array}$ \\
\hline ELECTRE & $\begin{array}{l}\text { - Outranking relation } \\
\text { - Threshold values } \\
\text { - Software availability }\end{array}$ & $\begin{array}{l}\text { - Incomparability among two } \\
\text { alternatives is possible } \\
\text { - Difficulty to understand the } \\
\text { procedure } \\
\text { - Arbitrary definition of the } \\
\text { outranking relation and the } \\
\text { threshold values } \\
\text { - Incomplete ranking of the } \\
\text { alternatives }\end{array}$ & {$[48,67,71]$} \\
\hline
\end{tabular}


Table 1: Continued

\begin{tabular}{|c|c|c|c|}
\hline Techniques & Advantages & Disadvantages & $\begin{array}{l}\text { Characteristic } \\
\text { applications }\end{array}$ \\
\hline PROMETHEE & $\begin{array}{l}\text { - Six alternative types of } \\
\text { preference functions to } \\
\text { model the decision-makers' } \\
\text { views } \\
\text { - Geometric representation of } \\
\text { the results } \\
\text { - Software availability }\end{array}$ & $\begin{array}{l}\text { - The selection of the } \\
\text { preference function cannot } \\
\text { be fully justified } \\
\text { - Not fully explicit process }\end{array}$ & [54] \\
\hline $\begin{array}{l}\text { REGIME } \\
\text { analysis }\end{array}$ & $\begin{array}{l}\text { - Complete ranking } \\
\text { - Software availability }\end{array}$ & $\begin{array}{l}\text { - Absence of threshold } \\
\text { values }\end{array}$ & {$[65,68]$} \\
\hline TOPSIS & $\begin{array}{l}\text { - Simple and easy to use } \\
\text { - Complete ranking }\end{array}$ & $\begin{array}{l}\text { - The result of the analysis is } \\
\text { very prone to changes at } \\
\text { criteria weights }\end{array}$ & {$[49,72]$} \\
\hline MAUT & $\begin{array}{l}\text { - Complete ranking } \\
\text { - The personal system of views } \\
\text { of the decision makers is } \\
\text { modelled }\end{array}$ & $\begin{array}{l}\text { - Increased data } \\
\text { requirements, analytical } \\
\text { endeavour and total cost, } \\
\text { especially when many } \\
\text { decision makers participate } \\
\text { in the process } \\
\text { - The decision makers do not } \\
\text { feel comfortable to fully } \\
\text { reveal their personal system } \\
\text { of preferences }\end{array}$ & {$[56,57,69]$} \\
\hline FLAG model & $\begin{array}{l}\text { - It operates as a classification } \\
\text { procedure or as a } \\
\text { visualization technique } \\
\text { - The suggested solution } \\
\text { achieves the minimum } \\
\text { accepted performance } \\
\text { - Three possible } \\
\text { representations of the results: } \\
\text { qualitative, quantitative and } \\
\text { the hybrid approach }\end{array}$ & $\begin{array}{l}\text { It is based on the analyst's } \\
\text { intuition for the definition } \\
\text { of the critical threshold } \\
\text { values } \\
\text { Incomplete ranking of the } \\
\text { alternatives }\end{array}$ & [65] \\
\hline
\end{tabular}

\section{CONCLUSIONS}

The article examines the possibility of the potential application of MCA to the evaluation of transport projects. It was established that the suggested methodology is flexible, transparent and user-friendly. It is flexible, because it allows modifications to take place at any stage of the process; transparent, because it provides an explicit 'audit trail' justifying all the reasons for preferring one 
choice over another. User-friendliness is a rather subjective attribute, but the applications described previously indicate that most practitioners and decision makers tend to feel comfortable using MCA to deal with the evaluation of a transportation project.

Additionally, the methodology discussed facilitates the assessment of transport projects from an environmental, social and economic perspective. In that respect, it contributes to the global goal of sustainability on the one hand and evaluates the problem in a multi-dimensional level on the other hand. Therefore, a further use of the MCA methodology is expected for the evaluation of transport projects as an alternative to the conventional CBA.

The article also presents, in short, the role of MCA in the evaluation process of transport projects. The most commonly used techniques to implement the analysis were also surveyed and included in this article. It was observed that a large number of MCA techniques have been developed to facilitate the process of sustainable development. Although the different procedures developed may be considered as a strong point of MCA, it can also be a weakness. More analytical endeavour is necessary to choose the appropriate technique to deal with a given evaluation problem.

Therefore, the article presented a comparative evaluation of the techniques. To do so, the examination of real-world applications was necessary. The examination of the case studies revealed that a gap often occurs between scientific procedure and business or policy practice. The results of theoretical research sometimes cannot be used in practice since the language might be too scientific or it might be remote from existing reality. It is not always easy to embody the limitations of the realworld conditions in the evaluation problem.

The study of the applications of the methodology also indicated that there is not only one set of fixed criteria that can be used to serve the concept of sustainability. The case studies revealed that a general set of 'benchmarks' exists, out of which criteria have to be defined according to the situation and the framework conditions posed by the specific problem in question.

It is notable that the simplification of the problem, to make it understandable for all the persons involved in the process, reduces the complexity on the one hand but on the other hand causes loss of important information. Consequently, attention should be given to the outcomes of MCA to reflect the real nature of the problem and satisfy the concept of sustainable development.

When one has to choose the appropriate technique without adequate information, the use of the analytical hierarchy process is strongly advised. This is due to the fact that in most of the cases included in this article this technique was used, which is a strong evidence for the appropriateness of the technique to facilitate the process of sustainable development. It is also suggested, when it is possible, to use more than one technique. If the results of the different procedures are similar, then the analyst may suggest that the proposed solution serves the concept of sustainability.

It is always advisable to perform a sensitivity analysis to examine how prone the product of the analysis to changes of the input data is. In most case studies, the modification involved changes of the weights given to the adopted criteria. In few case studies, changes took place at the performance of the suggested options against the criteria.

The participation of people with different and often contradictory views of the process is necessary to ensure the objective of sustainability. These people should express the different demands and preferences of the different groups of the society affected by the transport project.

An interesting conclusion is that many case studies involve the evaluation of public transportation systems and road transport projects. Public transport has an enormous social aspect and therefore there is a demand that the evaluation should include all the relative consequences, monetary and non-monetary. Thus, the common use of MCA is explained. On the other hand, the road projects pose a great amount of negative effects to the environment. Therefore, the methodology is used to include all the relevant parameters in the evaluation. 


\section{REFERENCES}

[1] Omann, I., Multi-Criteria Decision Aid as an Approach for Sustainable Development Analysis and Implementation, Karl-Franzes University, Graz, 2004.

[2] Bouwman, M. \& Moll, H., Environmental analyses of land transportation systems in the Netherlands. Transportation Research, 4(7), pp. 331-345, 2002.

[3] Hirschberg, S., Dones, R., Heck, T., Burgherr, P. \& Bauer, C., Sustainability of Electricity Supply Technologies Under German Conditions: A Comparative Evaluation, Paul Scherrer Institut: Berricht, 2004.

[4] Arrow, K.J., Social Choice and Individual Values, Wiley: New York, 1951.

[5] Doumpos, M. \& Zopounidis, C., Multicriteria Analysis: Theory and Applications, Kleidarithmos: Athens, 2001.

[6] Wolfslehner, B., Potentials and Limitations of Multi-Criteria Analysis Methods in Assessing Sustainable Forest Management, Department of Forest and Soil Sciences, Institute of Silviculture, University of Natural Resources and Applied Life Sciences, Vienna, Austria, 2006.

[7] Nijkamp, P., Stochastic quantitative and qualitative multicriteria analysis for environmental design. Papers in Regional Science, Springer: Berlin/Heidelberg, 2005.

[8] Treitz, M., Production Process Design Using Multi-Criteria Analysis, University of Karlsruhe, Germany, 2006.

[9] Bertsch, V., Treitz, M., Geldermann, J. \& Rentz, O., Multidimensional Sensitivity Analysis for Multi-Attribute Decision Making Under Preferential Uncertainty, Institute for Industrial Production, University of Karlsruhe, Germany, 2006.

[10] French, S., Uncertainty and imprecision: modelling and analysis. Journal of the Operational Research Society, 46, pp. 70-79, 1995.

[11] Montibeller, G. \& Belton, V., Qualitative Operators for Reasoning Maps: Evaluating MultiCriteria Options with Networks of Reasons, The London School of Economics and Political Science: London, 2007.

[12] Belton, V. \& Gear, T., On a short-coming of Saaty's method of analytic hierarchies. Omega, 11(3), pp. 228-230, 1983.

[13] Samuelson, P.A., The empirical implications of utility analysis. Econometrica, 6, pp. 344-356, 1938.

[14] Luce, R.D. \& Raiffa, H., Games and Decisions, Wiley: New York, 1957.

[15] Fishburn, P.C., Utility for Decision Making, Wiley: New York, 1970.

[16] Roy, B., Classement et choix en precense de points de vue multiples: la methode ELECTRE. R.I.R.O., 8, pp. 57-75, 1968.

[17] Simon, H.A., From substantive to procedural rationality. Method and Appraisal in Economics, ed. S.J. Latsis, Cambridge University Press: Cambridge, pp. 129-148, 1976.

[18] Keeney, R.L. \& Raiffa, H., Decisions with Multiple Objectives, Wiley: New York, 1976.

[19] Saaty, T.L., The Analytical Hierarchy Process, McGraw-Hill: New York, 1980.

[20] Tsamboulas, D., Yiotis, G. \& Roilos, H., Potential application and inclusion of quantitative qualitative criteria in a multi-criteria analysis for the assessment of transport projects. Technika Chronika, 1(3), pp. 35-49, 1999.

[21] DTRL, Multi-Criteria Analysis Manual, UK.

[22] Pardalos, P.M., Siskos, Y. \& Zopounidis, C., Advances in Multicriteria Analysis, Kluwer Academic Publishers: Dordrecht, Boston and London, 1995.

[23] Schoner, B. \& Wedly, W.C., Ambiguous criteria weights in AHP: consequences and solutions. Decision Sciences, 20, pp. 462-475, 1989. 
[24] Millet, I. \& Saaty, L., On the relativity of relative measures - accommodating both rank preservation and rank reversals in the AHP. European Journal of Operational Research, 121, pp. 205-212, 2000.

[25] Schoner, B. \& Wedly, W.C., A unified approach to AHP with linking pins. European Journal of Operational Research, 64, pp. 384-392, 1993.

[26] Bouyssou, D., Marchant, T., Pirlot, M., Perny, P., Tsoukias, A. \& Vincke, P., Evaluation and Decision Model: A Critical Perspective, Kluwer Academic Publishers: Boston, London and Dordrecht, 2002.

[27] Brans, J.P. \& Vincke, P., A preference ranking organization method. Management Science, 31(6), pp. 647-656, 1985.

[28] Massaglia, M. \& Ostanello, A., N-TOMIC: a decision support for multicriteria segmentation problems, International Workshop on Multicriteria Decision Support, Springer-Verlag: Berlin, pp. 167-174, 1991.

[29] Belacel, N., Multicriteria assignment method PROAFTN: methodology and medical applications. European Journal of Operational Research, 5, pp. 179-199, 2000.

[30] Roubens, M., Preference relations on actions and criteria in multicriteria decision making. European Journal of Operational Research, 10, pp. 51-55, 1982.

[31] European Union, SAMI project, Deliverable 2: Review of Strategic Assessment Tool and Methods, Fourth Framework Programme, 1998.

[32] Xiaozhan, X., The SIR method: A superiority and inferiority ranking method for multiple criteria decision making. European Journal of Operational Research, 131, pp. 587-602, 2001.

[33] Chen, S.J. \& Hwang, C.L., Fuzzy Multiple Attribute Decision Making: Methods and Applications, Springer-Verlag: Berlin, 1992.

[34] Opricovic, S., Multicriteria Optimization of Civil Engineering Systems, Faculty of Civil Engineering: Belgrade, 1998.

[35] Jacquet-Lagreze, E. \& Siskos, J., Assessing a set of additive utility functions for multicriteria decision making, the UTA method. European Journal of Operational Research, 10, pp. 151-164, 1982.

[36] Greco, S., A new PCCA method: IDRA. European Journal of Operational Research, 98, pp. 587-601, 1997.

[37] Charnes, A., Cooper, W. \& Rhodes, E., Measuring the efficiency of decision making units. European Journal of Operation Research, 2, pp. 429-444, 1986.

[38] Haimes, Y.Y., Hall, W.A. \& Freedman, H.T., Multiobjective Optimization in Water Resources Systems, Elsevier Scientific: New York, 1975.

[39] Goumas, M. \& Lygerou, V., An extension of the PROMETHEE method for decision making in fuzzy environment: Ranking of alternative energy exploitation projects. European Journal of Operational Research, 123, pp. 606-613, 2000.

[40] Zadeh, L.A., Fuzzy sets. Information and Control, 8, pp. 338-353, 1965.

[41] Lahdelma, R., Hokkanen, J. \& Salminen, P., SMAA - Stochastic multiobjective acceptability analysis. European Journal of Operational Research, 106, pp. 137-143, 1998.

[42] Pawlak, Z., Rough sets. International Journal of Information and Computer Sciences, 11, pp. 341-356, 1982.

[43] Paelinck, J.H.P., Qualiflex, a flexible multiple criteria method. Economics Letters, 3, pp. 193-197, 1978.

[44] Voogd, H., Multicriteria Evaluation for Urban and Regional Planning, Pion: London, 1983.

[45] Mashrur, A., Paulin, T. \& Surekha, L., An Interactive Multiobjective Decision Support Framework for Transportation Investment, Department of Civil and Environmental Engineering and Engineering Mechanics, University of Dayton, Dayton, 2002. 
[46] Yedla, S. \& Shrestha, R., Multi-criteria approach for the selection of alternative options for environmentally sustainable transport system in Delhi. Transportation Research, 37, pp. 717-729, 2003.

[47] Arampatzis, G., Kiranoudis, C.T., Scaloubacas, P. \& Assimacopoulos, D., A GIS-based decision support system for planning urban transportation policies. European Journal of Operational Research, 152, pp. 465-475, 2004.

[48] Massam, B., The search for the best alternative using multiple criteria, Singapore Transit Study, Economic Geography, 54(2), pp. 245-253, 1978.

[49] Tzeng, G.H., Lin, C.W \& Opricovic, S., Multi-criteria analysis of alternative fuel buses for public transportation. Energy Policy, 33, pp. 1373-1383, 2005.

[50] Hinloopen, E., Nijkamp, P. \& Rietveld, P., Integration of ordinal and cardinal information in multicriteria ranking with imperfect compensation, European Journal of Operational Research, 158, pp. 317-338, 2004.

[51] Transport for London Integration, Greenwich Waterfront Transit, Summary Report, London, 2001.

[52] Gercek, H., Karpak, B. \& Kilincaslan, T., A multiple criteria approach for the evaluation of the rail transit networks in Istanbul. Transportation, 31, pp. 203-228, 2004.

[53] Zak, J., The methodology of multiple-criteria decision making in the optimization of an urban transportation system: case study of Poznan City in Poland. International Transactions in Operational Research, 6, pp. 571-590, 1999.

[54] Grassini, L. \& Viviani, A., A Multicriteria Decision Method to Evaluate Local Transport Service, University of Florence, Florence, 2002.

[55] Yeh, C., Deng, H. \& Chang, Y., Fuzzy multicriteria analysis for performance evaluation of bus companies. European Journal of Operational Research, 126, pp. 459-473, 2000.

[56] European Commission, TRANSECON Project, Deliverable 2, Helsinki, 2003.

[57] Cascajo, R., Assessment of Economic Social and Environmental Effects of Rail Urban Projects, Transport Research Center, Universidad Politécnica de Madrid, Madrid, 2004.

[58] Tsamboulas, D. \& Mikroudis, G., EFFECT-evaluation framework of environmental impacts and costs of transport initiatives. Transportation Research, 5, pp. 283-303, 2000.

[59] Panou, K.D. \& Sofianos, A.I., A fuzzy multicriteria evaluation system for the assessment of tunnels vis-à-vis surface roads: theoretical aspects - part II. Tunneling and Underground Space Technology, 17, pp. 209-219, 2002.

[60] Juan, Z. \& Wu, J., The socio-economic impacts assessment of advanced convoy driving on motorway. Transportation Research, 37, pp. 731-747, 2003.

[61] Fuller, D.O., Williamson, R., Jeffe, M. \& James, D., Multi criteria evaluation of safety and risks along transportation corridors on the Hopi Reservation, Applied Geography, 23, pp. 177-188, 2003.

[62] Bailey, K., AMIS: Development and Application of a GIS/Multicriteria Corridor Evaluation Methodology, Department of Geography and Regional Development, University of Arizona, Arizona, 2003

[63] Tsoukias, A. \& Papayannakis, A., A Real Case Study on Transportation Scenario Comparison, TRUTH S.A.: Thessaloniki, 2001.

[64] Brown, K., Adger, N., Tompkins, E., Bacon, P., Shim, D. \& Young, K., Trade-off analysis for marine protected area management. Ecological Economics, 37, pp. 417-434, 2001.

[65] Vreeker, R., Nijkamp, P. \& Welle, C., A multicriteria Decision Support Methodology for Evaluating Airport Expansion Plans, Tinbergen Institute: Amsterdam, 2001.

[66] Levine, J. \& Underwood, S., A multi-attribute analysis of goals for intelligent transportation system planning, Transportation Research, 4(2), pp. 97-111, 1996. 
[67] Ukkussuri, S., Karoonsoontawong, A., Waller, S. \& Kockelman, M., Congestion pricing technologies: synthesis and an evaluation framework. Proc. of the 2005 Annual Meeting of the Transportation Research Board, 2004.

[68] Reggiani, A., Lampugnani, G., Nijkamp, P. \& Pepping, G., Towards a typology of European inter-urban transport corridors for advanced transport telematics applications. Journal of Transport Geography, 3(1), pp. 53-67, 1995.

[69] Haynes, K., Bowen, W., Arieira, C., Burhans, S., Salem, P. \& Shafie, H., Intelligent transportation systems benefit priorities: an application to the Woodrow Wilson bridge. Journal of Transport Geography, 8, pp. 129-139, 2000.

[70] European Commission, Regional Balkans Infrastructure Study - REBIS, 2000 CARDS Programme, Final Report, 2003.

[71] Louis Berger, S.A., Transport Infrastructure Regional Study (TIRS) in the Balkans, Final Report, 2002.

[72] Janic, M., Multicriteria evaluation of high-speed rail, transrapid MAGLEV and air passenger transport in Europe. Transportation Planning and Technology, 26(6), pp. 491-512, 2003.

[73] Makridakis, C.M., Applications of Multi-Criteria Analysis Techniques to the Evaluation of Transport Projects, M.Sc. Thesis, Supervisor: S. Basbas, Postgraduate Program: Planning, Organization and Management of Transport Systems, Faculties of Civil Engineering \& Rural and Surveying Engineering, Aristotle University of Thessaloniki, Thessaloniki, 2005. 